\title{
NOVOS DIREITOS, ONDAS RENOVATÓRIAS E JURISDIÇÃO CIVIL
}

http://dx.doi.org/10.21527/2176-6622.2021.55.265-277

Recebido em: 19/11/2019

Modificações solicitadas em: 20/4/2020

Aceito em: 9/11/2020

Thiago Feiten Nunes

Autor correspondente. Universidade Federal de Santa Maria. Av. Roraima, no 1000 - Cidade Universitária Bairro Camobi, CEP 97105-900. Santa Maria/RS, Brasil. http://lattes.cnpq.br/6172492223216753. https://orcid.org/0000-0002-6668-6119.nunes_127@hotmail.com

Cristiano Becker Isaia

Universidade Federal de Santa Maria. Santa Maria/RS, Brasil.

\section{RESUMO}

Este trabalho apresenta uma possibilidade de adequação da jurisdição processual civil à modernidade. Por meio de um estudo teórico, procurou-se demonstrar as incongruências ideológicas havidas no âmbito do Direito Processual Civil brasileiro em contraposição à eclosão de novos direitos em pleno século 21 . Em que pesem as reformulações legislativas recentes, o modelo processual, ora vigente, congrega valores individualistas, patrimonialistas e liberais, com nítida crença em um rito ordinarizado como caminho necessário à produção de uma decisão coerente. Por outro lado, tem-se as ondas renovatórias como conjunto proposto para efetivar o acesso à Justiça dentro do sistema jurídico. O propósito do questionamento a ser levantado nesta obra é de que o objetivo de todos os movimentos de acesso à Justiça é humanizar o mecanismo processual, além de atender aos anseios do Estado Democrático de Direito e buscar extinguir métodos que dificultem o acesso por parte da população. O que se vislumbra, assim, é a necessidade de aprimoramento de tal sistema jurisdicional, com a elaboração de procedimentos sumarizados e democratizados. O trabalho está dividido em dois tópicos, tratando, respectivamente sobre: (i) o diagnóstico do estado da arte do processo civil brasileiro e as ondas renovatórias de Mauro Cappelletti e Bryant Garth; (ii) os caminhos para o protagonismo da jurisdição processual por meio de tais ondas. Salientando, nesta obra, que o acesso à Justiça não perfaz apenas a busca por mecanismos de provocação ou exercício do direito de ação, mas também de tutela jurisdicional rápida, efetiva e compativel materialmente com o Direito questionado em juízo. A estratégia metodológica tem caráter hermenêutico-fenomenológico.

Palavras-chave: Jurisdição. Ondas renovatórias. Constituição.

\section{NEW RIGHTS, RENEWAL WAVES AND CIVIL JURISDICTION}

\section{ABSTRACT}

This paper presents a possibility of constitutionalization of civil procedural jurisdiction. Through a theoretical study, we tried to demonstrate the ideological incongruities in the Brazilian civil procedural law as opposed to the valuation charge provided for in the 1988 Federal Constitution. In spite of recent legislative reformulations, the procedural model, now in force, congregates individualistic, patrimonial and liberal values, with a clear belief in an ordinarized rite as the necessary path to the production of a coherent decision. Moreover, the same system derives from the bourgeois ideals of the seventeenth century, in which the judge /interpreter would merely declare the law without the awareness of its effective realization in the empirical world. What can be seen, therefore, is the need to improve such a jurisdictional system, with the elaboration of summarized and democratized procedures, where there are spaces for effective action by the Judiciary, always in the concern to safeguard and give effectiveness and cohesion to rights. and fundamental guarantees. The work is divided into two chapters, dealing respectively with: the diagnosis of incongruities between constitution and civil process (the emergence of neoconstitutional reading and the state of the art of the Brazilian civil process) and the ways of (re) approximation between them, especially with the mention of the renewing waves of Mauro Cappelletti and Bryant Garth. Emphasizing, in this work, that the access to justice is not only the search for mechanisms of provocation or exercise of the right of action, but also of a fast, effective and materially compatible judicial protection with the right questioned in court.

Keywords: Jurisdiction. Renewable waves. Constitution.

\section{SUMÁRIO}

1 Introdução. 2 Novos direitos, processo civil e acesso à justiça. 2.10 estado da arte do processo civil brasileiro. 2.2 Acesso à Justiça e Ondas Renovatórias de Mauro Cappelletti e Bryant Garth. 3 Aplicação da segunda e terceira onda como caminhos de (re)aproximação do processo civil ao seu desiderato. 3.1 A atuação da segunda e terceira Onda Renovatória como condição de possibilidade para o protagonismo da jurisdição processual civil. 4 Conclusão. 5 Referências. 


\section{INTRODUÇÃO}

A civilização humana e o próprio Direito por ela produzido - e a ela aplicado - vêm sofrendo suas constantes adaptações aos novos contornos sociais emergentes de uma sociedade globalizada e multifacetada. Tal enredo, por sua vez, constantemente alterado pelo processo de complexização das relações intersubjetivas e dos mecanismos de produção, pugna por um campo jurídico atrelado ideologicamente, em um contexto de contínua adaptação.

Sob o ponto de vista dos direitos fundamentais não é diferente. Na linha evolucional de tais direitos, diante do contexto sociopolítico pujante, exsurge uma nova perspectiva quanto a seus titulares, no qual a democracia, a solidariedade e o caráter difuso se fazem presentes, representando verdadeiros baluartes em uma sociedade toda globalizada e conectada.

Nesse prisma, estas referidas pretensões fundamentais, sobretudo transindividuais, quando violadas necessitam de uma jurisdição estatal apta a tutelá-las. É nesse enfoque que, no âmbito jurídico, o papel do Direito Processual Civil assume relevante importância, perfazendo-se um ramo específico destinado a regulamentar o processo de atuação jurisdicional-estatal desencadeado pelo exercício do direito de ação previsto constitucionalmente (artigo 5o, XXXV). Tal área assume relevante papel teleológico ante o disposto no texto constitucional, uma vez que se consubstancia no mecanismo necessário à obtenção da tutela de direitos e garantias, principalmente na atual configuração estatal vigente por parte do poder Judiciário.

Ocorre que, a partir de um estudo preliminar acerca do referido ramo do Direito, sobretudo da análise da obra Processo e Ideologia: o paradigma racionalista, de Ovídio Baptista da Silva (2006), constata-se que o processo civil brasileiro, em que pesem as recentes tentativas de reformulação legislativa bem-vindas, ainda está mergulhado em uma crise. Isto, pois, pelo aprofundamento teórico inicial para o desenvolvimento do presente trabalho, percebe-se a existência de um déficit democrático na jurisdição processual, a qual, inserida nos moldes patrimonialistas e liberais do século 17 , mostra-se distante da real historicidade emergente, marcadas de transformações filosóficas, políticas e jurídicas ocorridas no seio do direito constitucional mundial no segundo pós-guerra.

Por outro lado, nesse cenário caótico, imprescindível é deixar emergir as influências advindas dos movimentos de acesso à Justiça, oriundos da década de 70 do século 20, nos quais o processo deve ser acessível e as técnicas processuais democratizadas, reforçando a tese de que o Direito Processual Civil deve ater-se às condições de tempo e espaço, a fim de se compatibilizar com o Direito pleiteado em juízo. A pretensão material, sem dúvidas, mostra-se, em tempos de direitos emergentes, mais volátil, acelerada, significativa e longe do rito e da ordinariedade ainda marcantes na formulação científica do processo civil.

O cerne do trabalho, então, estará em demonstrar que diante das modificações enfrentadas pela sociedade o Direito Processual Civil, como alavanca para a prestação jurisdicional e, consequentemente para a tutela do objeto litigioso, não pode mais coadunar-se com a temática individualista, conservadora e autoritária de dominação dos séculos anteriores. Necessária, portanto, é (re)leitura do acesso à jurisdição, calcado na obra de Mauro Cappelletti e Bryant Garth, a fim de buscar parametricidade entre processo civil e a real efetivação dos direitos materiais tutelados no bojo do procedimento.

Estruturalmente, o presente trabalho é dividido em dois tópicos. Na primeira parte demonstrar-se-á a existência de novos direitos, a inconsistência paradigmática do atual sistema processual civil posto, sobretudo mediante a abordagem da influência individualista, e a existência de ondas renovatórias de acesso à Justiça. Já no segundo item, com base nas constatações feitas, procurar-se-á elucidar alternativas de releitura à jurisdição processual civil, com ênfase nas Ondas Renovatórias de acesso à Justiça.

\section{NOVOS DIREITOS, PROCESSO CIVIL E ACESSO À JUSTIÇA}

Desde o início da evolução da racionalidade humana, a declaração e a consagração dos direitos fundamentais no ordenamento jurídico foram frutos de uma longa evolução da sociedade, sobretudo mediante perenes lutas e disputas entre governantes e governados. Ademais, essa gama histórica de garantias e direitos normatizados, ante a consolidação do positivismo provocada nos séculos 17 e 18, no curso natural do tempo, passou a exteriorizar-se por meio do processo de constitucionalização ocorrido no mundo, principalmente na sua esfera ocidental. Nesse viés é a primorosa formulação de José Gomes Canotilho: 
Mediante a positivização de determinados princípios e direitos fundamentais, na qualidade de expressões de valores e necessidades consensualmente reconhecidos pela comunidade histórica e espacialmente situada, o Poder Constituinte e a própria Constituição transformam-se em autêntica "reserva de justiça", em parâmetro da legitimidade ao mesmo tempo formal e material da ordem jurídica estatal [...] sendo o fundamento de validade da constituição e a dignidade de seu reconhecimento como ordem justa e a convicção, por parte da colectividade, da sua bondade instrínseca (CANOTILHO, 1998, p. 115).

Oportunamente, aduz Manoel Gonçalves Ferreira Filho (2009, p. 306) que "todo cidadão, com efeito, não pode desconhecer que existe uma lei suprema, imposta aos povos e a seus governantes, da qual resulta a dignidade humana e dela direitos fundamentais, inalienáveis e imprescritíveis." Nesse viés, para uma melhor compreensão do processo histórico e evolutivo pelo qual passou a humanidade, exteriorizar-se-á de forma muita sucinta a tão conhecida evolução dos direitos fundamentais. Tal iter evolutivo tem a intenção de propiciar apenas uma reflexão sobre as naturais e inevitáveis mudanças, sob as quais está condicionado o Direito, não nos revelando outra conclusão senão a de que os direitos fundamentais são valores, frutos de processo político e social, que recebem uma moldura jurídica com a finalidade de resguardo e não regresso.

Reforçando o sentido exposto são as palavras de Pérez Luño:

Los derechos humanos, en su acepción estricta, surgieron en el clima cultural ilustrado de la Modernidad. Fueron formulados entonces como categorias que pretendiam expresar las exigencias intemporales y perpetuas de la naturaleza humana; como un conjunto de facultades jurídicas y políticas propias de todos los hombres y en todos los tiempos. Ese paradigma eleático concebía los derechos humanos como unas verdades, cuya evidencia podía demostrarse a través de los dictámenes de la recta razón (2006, p. 13).

Sem prejuízo da diversidade de classificações existentes a respeito do número de gerações de direitos fundamentais, ${ }^{1}$ conforme afirma Paulo Bonavides, inegavelmente o lema da Revolução Francesa profetizou a sequência histórica da gradativa institucionalização dessa espécie de direitos, do qual decorre sua divisão em três gerações, ${ }^{2}$ sucessivamente: direitos da liberdade, da igualdade e da fraternidade (BONAVIDES, 2009, p. 562). Tais gerações manifestaram-se perante a ordem institucional de forma sequencial, traduzindo, verdadeiramente, um processo gradual, cumulativo e qualitativo, e assumindo, na medida em que foram evoluindo, uma postura cada vez mais concretizadora e efetiva em contradição à abstrativização antigamente vigente.

Assim, quanto à classificação, os direitos de primeira geração correspondem aos direitos da liberdade, referindo-se aos direitos civis e políticos, e tendo como titular o indivíduo. São direitos de resistência ou oposição contra o poder público, de modo a pressupor uma separação entre Estado e sociedade, na qual esta última exige daquele apenas uma abstenção, ou seja, uma obrigação negativa visando à não interferência na liberdade individual. ${ }^{3}$

Já os direitos da segunda geração são os sociais, culturais e econômicos. Tal espécie é advinda da coletividade em si, pois derivam do princípio da igualdade, e apresentam seu surgimento aliado ao Estado social. São pretensões que exigem determinadas prestações estatais, fato que inevitavelmente ocasiona interrogações a respeito de sua aplicabilidade imediata, pois nem sempre o organismo estatal possui meios suficientes para cumpri-los. ${ }^{4}$

\footnotetext{
${ }^{1}$ A existência de variáveis doutrinárias, quanto ao número de gerações de direitos fundamentais, é facilmente detectada pelas obras de Antonio Enrique Pérez Luño, Paulo Bonavides, Ingo Wolfgang Sarlet e José Luís Bolzan de Moraes.

2 No presente trabalho utilizar-se-á o vocábulo "geração" como sinônimo de "dimensão", sem adentrar no conflito terminológico promovido pela doutrina especializada, em que há o posicionamento por um ou outro termo em razão da manutenção da historicidade entre as gerações. O que resta evidente, importante frisar, é que gerações de Direito não significam a sobreposição de uma sobre a outra, fadando a mais remota ao esquecimento, mas sim, uma existência concomitante, diferenciando-se apenas quanto ao momento de sua inserção no Direito posto.

3 Podem ser citados como exemplos de direitos fundamentais de primeira geração os direitos à vida, à liberdade e à igualdade, previstos no caput do artigo 5ㅇ da Constituição Federal de 1988. Derivados de tais direitos, também podem ser destacados como direitos de primeira geração na Constituição brasileira as liberdades de manifestação (artigo 5o, IV), de associação (artigo 50, XVII) e o direito de voto (artigo 14 , caput).

${ }^{4}$ Como exemplo da segunda geração de direitos fundamentais, a Constituição brasileira prevê no artigo 5o, §1ㅇa a autoaplicabilidade das normas definidoras dos direitos e garantias fundamentais. Na Carta Magna de 1988 tais direitos estão elencados em capítulo próprio, denominado "Dos direitos sociais", onde estão descritos diversos direitos fundamentais, entre os quais os direitos à educação, saúde, trabalho, moradia, lazer, segurança e previdência social (artigo 6으, caput).
} 
Nesta esteira evolutiva, novos conceitos de direitos fundamentais passam a ser objetivados. Novamente, segundo Paulo Bonavides, "o Estado passou a ter a obrigação de criar pressupostos fáticos para a realização dos direitos, indispensáveis ao pleno exercício da liberdade, sobre os quais o indivíduo já não tem propriamente o poder. Tais pressupostos começam a inspirar também a legislação de direitos fundamentais constante de tratados, pactos e convenções internacionais" (BONAVIDES, 2009, p. 573). Assim sendo, a globalidade torna-se personagem importante nesse desencadeamento evolutivo de valores mínimos a serem tutelados, de modo que a atuação jurídica em prol da normativização de tais fundamentos começa a pertencer a uma comunidade de Estados e não mais a um Estado em particular.

Ademais, seguindo esse curso histórico, assentados sobre os valores da fraternidade e solidariedade, surgem os ditos direitos fundamentais de terceira geração, de natureza difusa, os quais visam à proteção do ser humano em si, e não apenas do indivíduo ou do Estado em nome da coletividade. Nas palavras de Ingo Sarlet, a nota distintiva dessa dimensão de direitos reside na titularidade coletiva, muitas vezes indeterminada ou indefinida, a qual, em que pese possa ficar preservada sua dimensão individual, reclama novas técnicas de garantia e proteção, o que se revela, a título de exemplo, no direito ao meio ambiente (SARLET, 2010, p. 49).

Com efeito, são identificados alguns exemplos não taxativos de direitos fundamentais de terceira geração, podendo, entretanto, surgirem outros direitos pertencentes a essa mesma geração, à medida que o processo universalista for se desenvolvendo: o direito ao desenvolvimento, à paz, ao meio ambiente, o direito de propriedade sobre o patrimônio comum da humanidade e o de comunicação, o direito do consumidor, a biotecnologia, a nanotecnologia, a bioengenharia, etc.

Ainda, apenas a título de complementação, alguns autores têm admitido a existência de uma quarta geração de direitos fundamentais. Nesse sentido, enaltece Bonavides:

Em meio a uma sociedade que caminha rumo a uma globalização econômica neoliberal, cuja filosofia de poder é negativa e intenta a dissolução do Estado Nacional debilitando os laços de soberania, os direitos de quarta geração surgem junto à globalização política na esfera da normatividade jurídica. São eles os direitos à democracia, à informação e ao pluralismo. Tais direitos formam o ápice da pirâmide dos direitos fundamentais (2009, p. 580).

Assim, diante do panorama histórico resumidamente tracejado, resta evidente a proliferação e fixação, entre o rol de direitos fundamentais, de uma série de pretensões transindividuais, dinâmicas, redimensionadas pelas contingências do nosso mundo global atual. Nesse diapasão, levando em consideração o atual paradigma de Estado Constitucional de Direito, e a força normativa relegada à Constituição, ocupando posição de supremacia absoluta dentro do ordenamento jurídico, imperiosa é a adequação/reformulação de toda atuação jurisdicional e da legislação infraconstitucional vigente no país a fim de resguardar, dar efetividade e, de fato, materializar a proteção dos respectivos direitos fundamentais transindividuais.

\subsection{0 estado da arte do processo civil brasileiro}

Diante do contexto de surgimento de novos direitos, sobretudo os transindividuais, conforme já ressaltado nas linhas anteriores, surgem maiores desafios à atuação jurisdicional ante a complexidade e/ou a extensão das demandas colocadas a seu crivo decisório. Assim, em um diapasão ainda mais específico, o papel da legislação processual civil, disciplina do Direito formal/instrumental, desponta como protagonista no cenário jurídico, desfrutando de condição inigualável de responsável por orientar a temporalidade existente entre o exercício de uma pretensão, no âmbito judicial, e a real efetivação da mesma por uma decisão do poder Judiciário.

A necessidade do processo judicial representa um custo para todos os titulares de direitos ou de outros interesses legalmente protegidos pela ordem jurídica estatal, à medida que, estabelecido o monopólio da jurisdição, como uma decorrência natural da formação do Estado, afasta-se definitivamente a possibilidade das reações imediatas tomadas pelos titulares para a pronta observância e realização do próprio direito (SILVA, 2000, p.13).

Ao fim e ao cabo, o Direito Processual Civil visa a resguardar a própria ordem jurídica, atuando não somente na pacificação de conflitos e manutenção do império da lei e da paz social, mas também como veículo de proteção aos direitos individuais (THEODORO JÚNIOR, 2010, p. 4). É pela observância dos ditames da legis- 
lação de processo que o Estado põe em prática sua exclusividade no monopólio da jurisdição, disciplinando suas modalidades de atuação, instituindo órgãos de função jurisdicional e estabelecendo um leque de regras aos possíveis e reais demandantes.

Ocorre que, como todo e qualquer outro ramo da Ciência, o Direito também não está imune às contingências históricas, teóricas e sociais de evolução da humanidade, pelo contrário, parte da dinamização ocasionada pelo tempo para se alcançar a sua constante e ilimitada lapidação. Lamentavelmente, conforme se verá adiante, na atual quadra da História, em solo brasileiro desfruta-se de um ordenamento processual civil dissociado de historicidade, o qual guarda estreita relação com os ditames autoritários e patrimonialistas marcantes do Estado liberal do século 17 (SILVA, 2007, p. 90). ${ }^{5}$ Como bem salienta Cristiano Becker Isaia (2010, p. 19) a respeito dessa carga histórica, a sobreposição da razão como meio de acesso às verdades absolutas - ideário iluminista - influenciou invariável e diretamente tanto o Direito quanto o processo civil, de modo a confinar juristas a um mundo jurídico totalmente desvinculado do mundo da vida, do mundo social.

Antes, no entanto, de se procurar compreender as contingências racionalistas e liberais presentes no Direito Processual Civil brasileiro, necessário é o conhecimento, sob o ponto de vista histórico, sobre dois grandes acontecimentos que marcaram a humanidade na derrocada do mundo medieval anterior ao século 17 e no surgimento da modernidade: a) o Renascimento - período marcado por transformações em muitas áreas da vida humana, sobretudo na economia, na política e na religião, caracterizando a transição do feudalismo para o capitalismo - e, b) a Reforma Religiosa. Ambos os acontecimentos representaram marcos históricos que serviram de releitura e questionamento de tudo aquilo que se produziu anteriormente, além de inaugurarem um novo paradigma cultural para a humanidade.

$\mathrm{Na}$ época, o aparato econômico gerado pela sociedade burguesa, aspirante de riqueza no século 17, não poderia ficar servindo de amparo e fomento ao privilégio daqueles que possuíam diversas formas de decisão e condução do Estado - nobreza e clero. Era preciso criar mecanismos que assegurassem um respaldo maior à classe ascendente, como a normativização de direitos e deveres fundamentais. Assim sendo, a imposição de leis, regulamentos, consubstanciados no discurso de igualdade, liberdade e fraternidade, eram caminhos que a burguesia detinha para que se regulassem as relações de poder, a organização entre os cidadãos e, mormente, a constituição de uma nova mentalidade de Estado, baseado na lei.

No mesmo sentido, complementa Eduardo Capellari:

Com isso, iniciou-se na tradição jurídica ocidental a prática de criação dos manuais, as obras exegéticas do direito codificado, que acabou por promover a inversão das relações tradicionais entre direito natural e direito positivo, desconstituindo o direito natural; fortalecendo uma concepção rigidamente estatal do direito; reivindicando que a interpretação da lei deve ter como critério a intenção do legislador; a identificação completa do direito com a lei escrita, trazendo o culto ao texto da lei $(2004$, p. 46).

Embora, todavia, tida como garantidora de obrigações e pressuposto para segurança jurídica, essa normativização buscada pela sociedade emergente na Idade Moderna escondeu escopos tiranos, sobre os quais os detentores de poder, principalmente econômico, perfizeram do Direito seu instrumento de dominação. Isso se explica, pois, além de aspirar ao poder, a classe burguesa fez do corpo de leis um meio/instrumento para que não mais se perdesse esse império de poder, algo dotado de perenidade, que não permitisse retrocessos que abalassem suas prerrogativas já conquistadas.

No ponto, novamente, as palavras são de Ovídio Baptista da Silva:

Aqui, como em outros pontos, é necessário considerar que o predomínio do valor segurança, que constituiu sem dúvida o elemento preponderante na formação do conceito moderno de Direito, já estava presente, como a principal preocupação de legisladores dos séculos IV e $V$ da era cristã [...] Nesse particular, a revolução cultural formadora do mundo moderno valeu-se de elementos medievais, não significando, portanto, como à primeira vista poderia parecer, um rompimento definitivo e radical com os valores da Idade Média (2007, p. 102).

\footnotetext{
A título exemplificativo, tal paradigma, como menciona Ovídio Baptista, serve como fator fundamental para a ordinariedade processual que hoje se conhece, a qual não aceita a ideia de "execução" sem "cognição" antecedente, pois executar antes de conhecer seria uma forma de permitir que o juiz julgasse com base em simples verossimilhança, outorgando tutela a quem na realidade não fosse titular do direito.
} 
Assim, o predomínio absoluto do valor segurança, em detrimento do valor justiça, como polaridades antagônicas, tanto na constituição do Direito como na formação do espírito científico, resultou na completa submissão do pensamento jurídico aos métodos e princípios das ciências da natureza, ou das ciências lógicas, como a Matemática (SILVA, 2007, p. 89). O ponto da discórdia, com efeito, está no fato de que as ciências comprometidas com a História, com a cultura, e que pressupõem uma compreensão hermenêutica não podem se submeter a métodos puramente dogmáticos, artificiais historicamente e cartesianos, como sugere a corrente filosófica racionalista-liberal em comento.

Sob o viés técnico-prático, a aceitação do pressuposto de que a lei teria "vontade" de sentido unívoco é o que legitima, por exemplo, a presença de certos dispositivos legais em nosso Código de Processo Civil Brasileiro, como os artigos 1.036, ${ }^{6} 1.035, \S 80,7$ e 1.040, inciso I ${ }^{8}$ (BRASIL, 2015), uma vez que se evidencia um empreendimento a conferir imutabilidade - sentido único - a posicionamentos/decisões judiciais, ocasionando, nesse sentido, uma tentativa de manutenção do poder pelo próprio Direito, no caso, o processual. De plano percebe-se o grau de subjetividade e estandardização capaz de ser propiciado pelos mencionados dispositivos, perfazendo-se, com certeza, um verdadeiro mecanismo de controle, sobretudo no âmbito recursal do Direito Processual Civil, o qual se rege pelo conservadorismo e pela dificuldade em aceitar a mudança. ${ }^{9}$

Como bem exaltou o professor Lenio Streck a respeito do tema:

Todos os recursos contrários à "jurisprudência dominante", por exemplo, estarão, de plano, condenados ao arquivamento, provocando o "congelamento" da jurisprudência do Superior Tribunal de Justiça e, em especial, do Supremo Tribunal Federal, destinatário do recurso extraordinário-constitucional, bem como dos demais tribunais, a partir do fato de que também eles podem negar seguimento a recursos que contrariem suas próprias “jurisprudências dominantes (STRECK, 2002, p. 398).

No mesmo sentido, segundo Adalberto Hommerding (2007, p. 277), é preciso que se denunciem as reformas legislativas ad hoc, que têm levado, sistematicamente, à concentração do poder nos tribunais superiores. É nesse aspecto que se faz presente um dos problemas do acesso à Justiça, sonegando a partir de mecanismos como os constantes no artigo 932, "monocratizando" as decisões de segundo grau, que impedem o acesso aos tribunais superiores. O referido artigo transfere a competência originariamente dada ao colegiado para um relator, ímpar, a fim de fulminar a demanda com alto grau de subjetividade.

Ademais, quanto ao rito procedimental atualmente vigente na legislação processual brasileira, observações, no que tange à influência racionalista e liberal, também hão de ser feitas. Eis que este é o caminho de exercício natural da atividade jurisdicional, perfazendo-se também mecanismo encontrado pelo legislador para, ao mesmo tempo, abrigar alguns dogmas inautênticos que foram se agregando na construção do pensamento jurídico moderno e garantir formalmente uma objetividade no resultado. Constata-se, pela forma como foi concebido, que o procedimento ordinário - fase a fase $\mathrm{f}^{10}$ - revela-se expoente de ordinariedade, tendo como principais postulados a necessidade de uma cognição exauriente e um intocável contraditório prévio, ritualístico, cartesiano, como forma única de atingir a verdade, revelada na sentença.

Não se pugna, de maneira alguma, eliminação total da ordinariedade como saída ao processo civil brasileiro do século 21, mas sua adequação aos ditames expostos pelo Direito material, uma vez que é em prol deste último que se materializa a função de ser do Direito Processual. As novas espécies de direitos emergentes,

\footnotetext{
${ }^{6}$ Art. 1.036. Sempre que houver multiplicidade haverá afetação para julgamento de acordo com as disposições desta Subseção, observado o disposto no Regimento Interno do Supremo Tribunal Federal e no do Superior Tribunal de Justiça.

Art. 1.035. O Supremo Tribunal Federal, em decisão irrecorrível, não conhecerá do recurso extraordinário quando a questão constitucional nele versada não tiver repercussão geral, nos termos deste artigo.

${ }_{\S}^{8}$ o Negada a repercussão geral, o presidente ou o vice-presidente do Tribunal de origem negará seguimento aos recursos extraordinários sobrestados na origem que versem sobre matéria idêntica.

8 Art. 1.040. Publicado o acórdão paradigma:

I - o presidente ou o vice-presidente do Tribunal de origem negará seguimento aos recursos especiais ou extraordinários sobrestados na origem, se o acórdão recorrido coincidir com a orientação do tribunal superior;

9 São exemplos disso: artigo 120, parágrafo único; artigo 285-A, artigo469, II, artigo 515, §3ㅇ, artigo 527 I, artigo 557, caput e §1ํ-A, todos do Código de Processo Civil Brasileiro.

${ }^{10}$ Vide artigos. 282 a 475 do Código de Processo Civil Brasileiro.
} 
juntamente com a eclosão de pretensões transindividuais do segundo pós-guerra, por exemplo, acarretam a necessária edição de normas procedimentais diferenciadas, com certa flexibilização no grau de sua cognição e diferenciação de seu contraditório prévio, conforme se verá mais adiante.

Por outro lado, já no que respeita à variedade de procedimentos, o Código de Processo Civil Brasileiro, por exemplo, confere uma proteção especial à propriedade, à posse e ao crédito, ${ }^{11}$ deixando evidente sua característica individualista, patrimonialista e mantenedora de riqueza, sempre priorizando a classe dominante economicamente, indelével resquício trazido lá do século 17. Em que pese a importância dessas espécies de procedimentos, necessária é a reformulação da concepção de processo, de modo a materializar o texto constitucional sob outro aspecto, qual seja, a efetivação de direitos e garantias fundamentais. Referidos bens jurídicos, em um Estado Democrático de Direito, devem ocupar lugar de predominância diante dos anseios materialistas ora vigentes, o que, de fato, não ocorre no sistema processualista brasileiro.

O Direito Processual Civil vigente, portanto, não pode ficar preso aos ditames racionalistas do século 17, em que, além da utilização do Direito como mecanismo de manutenção do poder, a cognição exauriente e o contraditório prévio eram requisitos elementares - e nessa influência ao nosso sistema ainda são - para se desvendar a verdade sobre cada caso concreto. O primeiro deles, indubitavelmente é responsável pelo aprisionado do juiz ao procedimento, impossibilitado de efetivar direitos incompatíveis com tal, e o segundo impede uma tutela mais efetiva, rápida e eficaz ao sujeito ativo da relação processual.

Assim, consubstanciando-se cerne para o presente trabalho, essa readequação necessária do sistema jurisdicional aos valores e ideais constitucionais, com a inerente preocupação de se tutelar os novos direitos oriundos principalmente do pós-Segunda Guerra mundial, figura-se como protagonista do caminho de adaptação e vitalidade do Direito Processual Civil no século 21. É preciso haver uma compatibilização do direito formal, com as peculiaridades de urgência e extensão advindas do direito material emergente, de modo que uma série de desafios democratizantes, neste momento, sejam lançados à jurisdição processual civil na tentativa de readequá-la às complexas demandas que lhe exigem uma tutela satisfatória.

\subsection{Acesso à Justiça e Ondas Renovatórias de Mauro Cappelletti e Bryant Garth}

Especificamente sobre o tema de acesso à Justiça, tal nicho ganhou destaque na década de 70, quando estudiosos do Direito, e de várias outras áreas, concretizaram um projeto específico, levando em consideração diversas realidades mundiais. O resultado oriundo desses acontecimentos sociointelectuais restou conhecido como "Projeto Florença ${ }^{12 "}$ e as principais conclusões foram expostas na obra Acesso à Justiça, de autoria de Mauro Cappelletti e Bryant Garth (1988), que dividiram em três ondas os principais movimentos renovatórios do acesso à Justiça.

Cada dita "onda" representou um plexo de ideias, surgidas em lapsos temporais sucessivos, mas todas possuindo correlações. Na mencionada obra observou-se a preocupação dos autores com o problema do acesso dos indivíduos mais pobres ao poder Judiciário, à respectiva representatividade, por meio de advogados públicos ou privados, bem como a uma decisão justa e efetiva. A doutrina, à época, também previu o incentivo à adoção de políticas públicas e judiciárias voltadas para a tutela dos direitos difusos e coletivos, assim como o estímulo à solução alternativa de conflitos e à reestruturação ou criação de novos tribunais.

Com efeito, em termos legais/constitucionais, em âmbito brasileiro, o acesso à Justiça está consagrado no artigo 5, XXXV da CRFB nos seguintes termos:

“Art. 5ㅇ Todos são iguais perante a lei, sem distinção de qualquer natureza, garantindo-se aos brasileiros e aos estrangeiros residentes no país a inviolabilidade do direito à vida, à liberdade, à igualdade, à segurança e à propriedade, nos termos seguintes: (...)

XXXV - a lei não excluirá da apreciação do poder Judiciário lesão ou ameaça de direito" (BRASIL, 1988).

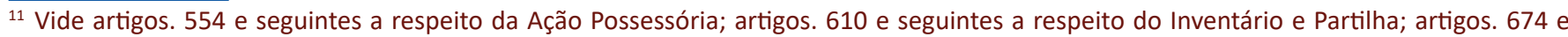
seguintes a respeito dos Embargos de Terceiro; e artigos. 700 e seguintes a respeito da Ação Monitória.

12 O "Projeto Florença" para o Acesso à Justiça foi elaborado com o escopo de estudar, sob um enfoque multidisciplinar, temas relevantes sobre acesso à Justiça. O "Projeto Florença" representou um novo paradigma epistemológico no estudo do Direito Processual, uma vez que não foi resultado de uma visão essencialmente teórica e hermeticamente fechada, trazendo ao leitor uma ótica positivamente influenciada pelo caráter sociológico do fenômeno jurídico.
} 
Além da Constituição Federal, o artigo 80 da 1a Convenção Interamericana sobre Direitos Humanos São José da Costa Rica - da qual o Brasil é signatário, também garante:

Art. 8‥ Toda pessoa tem direito de ser ouvida, com as garantias e dentro de um prazo razoável, por um juiz ou tribunal competente, independente e imparcial, estabelecido anteriormente por lei, na apuração de qualquer acusação penal contra ela, ou para que se determinem seus direitos ou obrigações de natureza civil, trabalhista, fiscal ou de qualquer natureza (OEA, 1969).

Observa-se que a Justiça brasileira, como a de outros países, também sofre, há considerável tempo, com o problema da ineficiência, especialmente na questão do acesso à Justiça, tanto no que diz respeito à representatividade e aos custos, quanto ao tempo de duração do processo. Necessário, a partir deste ponto, a apresentação sumária de cada uma das Ondas Renovatórias citadas anteriormente, a fim de desvendar se alguma delas pode ser útil ao exercício da jurisdição brasileira e de que forma podem ser efetivas no seu desiderato de acesso à Justiça. Passamos a analisá-las.

A primeira diz respeito à assistência judiciária aos pobres e está relacionada ao obstáculo econômico do acesso à Justiça. A segunda refere-se à representação dos interesses difusos em juízo e visa a contornar o obstáculo organizacional do acesso à Justiça. Já a terceira, denominada de "o enfoque do acesso à Justiça", detém a concepção mais ampla de acesso à Justiça e tem como escopo instituir técnicas processuais adequadas e melhor preparar estudantes e aplicadores do Direito.

\section{APLICAÇÃO DA SEGUNDA E TERCEIRA ONDA COMO CAMINHOS DE (RE) APROXIMAÇÃO DO PROCESSO CIVIL AO SEU DESIDERATO}

No presente esboço, em razão do que foi mencionado anteriormente, então, são propostos desafios, que nada mais é do que um ponto de questionamento tendente a alcançar uma remodelagem da jurisdição processual civil que atualmente vigora. Tal provocação, com o fito sempre mediato de, por meio da processualística, buscar-se a melhor e mais adequada tutela jurisdicional, se consubstancia na possibilidade de potencializar o acesso à Justiça como condição de possibilidade para se chegar a um processo mais efetivo e democrático, principalmente aos direitos sociais, coletivos, de meio ambiente, por exemplo, tidos como incongruentes ao atual paradigma processual.

Tal análise, diga-se de passagem, não surge de forma autônoma ou descabida, mas está atrelada aos próprios ditames oriundos da força normativa da Constituição e sua garantia fundamental de acesso à Justiça. Isso, pois, em meio ao contexto global atualmente evidenciado no âmbito do Direito, no qual o protagonismo judicial ganha relevante importância, ${ }^{13}$ é suprema a necessidade de que exista um Direito Processual alinhado ideologicamente a tal paradigma em vigor. Se não fosse assim, estaríamos fadados ao retrocesso. A previsão de um Direito Processual programático, vagaroso e não efetivo, e sobretudo inacessível, remeteria todas as evoluções alcançadas no âmbito constitucional lá para os primórdios do Positivismo, em que a prenúncio legislativo era tido como um fim em si próprio.

Com efeito, leciona Dierle Nunes:

Nos termos postos, não se torna mais possível pensar no processo civil em perspectiva dogmática e técnica, eis que, além de permitir a resolução de conflitos privados, ele se presta a viabilizar o exercício de direitos fundamentais. Ademais, não se pode mais realizar interpretações do sistema processual sem tomar por base o "modelo constitucional de processo" e sem perceber que além de se buscar a eficiência (geração de resultados úteis) há se de buscar uma aplicação que implemente a percepção dinâmica das normas constitucionais, lidas de modo a permitir participação e legitimidade em todas as decisões proferidas (NUNES, 2011, p. 37).

\footnotetext{
${ }^{13}$ Ante a inércia e omissão legislativa, demandas tratando-se de direitos fundamentais são levadas aos tribunais a fim de que possam ser postas em prática: vide ADPF no 54 - que trata do aborto de anencéfalos - e ADPF no 132 e ADIN no 4.277 - as quais abordam a união estável por pessoas do mesmo sexo.
} 
Assim, diante das constatações traçadas no tópico anterior, elucidando os traços liberais que ainda afetam o Direito Processual Civil brasileiro como um todo, faz-se importante questionar, então, alguns possíveis desafios para constitucionalizar a jurisdição processual civil. Tal análise partirá do apontamento de prováveis incongruências, marcantes no seio do ramo processual, reforçando-se a importância de se prestigiar as Ondas Renovatórias de acesso à Justiça trazidas da década de 70 por Mauro Cappelletti e Bryant Garth.

\subsection{A Atuação da Segunda e Terceira Onda Renovatória Como Condição de Possibilidade Para o Protagonismo da Jurisdição Processual Civil}

Como é sabido, o processo ${ }^{14}$ tem vínculo direto com os fins da jurisdição e com os direitos dos cidadãos, assumindo inegável papel de mecanismo de exteriorização da ideologia estatal que prepondera (SILVA, 2000, p. 34). Assim, no atual Estado Democrático de Direito deve destacar-se por seu caráter transformador, sendo relegado a instrumento de pacificação, efetividade social e protetor de direitos fundamentais (THEODORO JÚNIOR, 2002, p. 2).

Segundo Adalberto Hommerding (2007, p. 90), inserido na tradição liberal-individual-privatista e normativista, própria do Estado Liberal, o processo civil pátrio, em pleno Estado Democrático de Direito, não tem sido efetivo, na medida em que sua instrumentalidade não foi desvelada. Argumente o autor, na sequência, que o processo civil ainda não consegue atender à realização dos direitos fundamentais, na medida em que a estabilização jurídica que propicia é uma segurança voltada para o passado, sem qualquer compromisso com o presente ou com o futuro. Numa sociedade caracterizada pela rapidez das trocas econômicas, pelo risco pelas incertezas, o compromisso de tal ramo deveria ser com a efetividade, conciliando celeridade e segurança.

Assim, sem apresentar um esgotamento do tema, a partir de uma análise de contrapontos, procurar-se-á evidenciar a contribuição de cada uma destas ditas "ondas" para obter-se uma aproximação entre a jurisdição processual civil e os anseios atuais, sem prejuízo, contudo, de advertir que não existe uma única linha teórica para tanto. De fato, observar-se-á que as Ondas Renovatórias de acesso à Justiça trazidas lá da década de 70 por Mauro Cappelletti e Bryant Garth contribuem para esse processo de parametricidade ideológica do processo civil com a modernidade.

Isto posto, o atendimento mais efetivo aos direitos fundamentais oriundos da modernidade perpassa por modificação nos atores processuais (2a Onda Renovatória) e das técnicas processuais utilizadas até hoje (3a Onda Renovatória). Como se observa, ao tratar sobre a representação dos interesses difusos em juízo e técnicas processuais, a segunda e a terceira Onda Renovatória trazem consigo ampla correlação com o exercício da jurisdição civil e sua inerente função de resguardar direitos. Ao fim e ao cabo, a aplicabilidade do Direito Processual Civil a casos envolvendo cada vez mais titulares difusos, utilizando-se, sobretudo, de técnicas procedimentais diferenciadas, apresenta-se como um grande desafio à jurisdição civil no século 21 .

Passamos, pois, à análise sucinta de cada uma delas.

Denominada doutrinariamente de "segunda onda", a "Representação dos interesses difusos" detém o foco de preocupação especificamente nos interesses difusos, forçando a reflexão sobre noções básicas do processo civil e sobre o papel dos tribunais. A preocupação desta segunda onda resultou da incapacidade de o processo civil tradicional, de cunho individualista, servir para a proteção dos direitos ou interesse difusos ou também denominados de coletivos. É que o processo civil foi sempre visto como campo de disputa entre particulares, tendo por objetivo a solução de controvérsia entre eles a respeito de seus próprios interesses individuais.

\section{De acordo com Michele Damasceno Marques Mello,}

(...) Tal onda renovatória permitiu a mudança de postura do processo civil, que, de uma visão individualista, funde-se em uma concepção social e coletiva, como forma de assegurar a realização dos "direitos públicos" relativos a interesses difusos. (...) Essa nova concepção do direito pôs em relevo a transformação do papel do

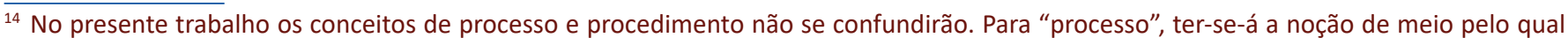
se vale o Estado para cumprir a função jurisdicional, sendo, assim, o instrumento da jurisdição. Já o "procedimento" considerar-se-á o conjunto de atos concatenados, de que se constitui o processo, com base em disposições legais e que dizem respeito à forma, à sequência, ao lugar e à oportunidade.
} 


\section{Direito自

juiz, no processo, e de conceitos básicos como a citação e o direito de defesa, na medida em que os titulares de direitos difusos, não podendo comparecer a juízo - por exemplo, todos os interessados na manutenção da qualidade do ar em uma determinada região - é preciso que haja um "representante" adequado para agir em benefício da coletividade. A decisão deve, em tais casos, ser efetiva, alcançando todos os membros do grupo, ainda que não tenham participado individualmente do processo" (2010).

Com efeito, atualmente, em pujante esperança, a referida segunda Onda Renovatória encontra seus reflexos no Direito Processual brasileiro por meio de mecanismos havidos para tutelar os direitos transindividuais, entre eles: a ação popular, mandado de segurança coletivo, o Código de Defesa do Consumidor e a Lei de Ação Civil Pública. Sem prejuízo, também são exemplos da influência do Projeto Florença, a Lei no 9.099/95 (Juizados Especiais Estaduais), Lei no 10.259/01 (Juizados Especiais Federais) e Lei no 9.307/96 (Arbitragem).

Como se constata o plexo de informações trazidas pela 2a onda "cappellettiana", além de propiciar o acesso à Justiça a direitos transindividuais, enaltece o caráter democrático do processo civil, pois proporciona o exercício de pretensões contramajoritárias, tidas por pessoas com menos acesso a ele. Ainda, as inovações legislativas trazidas por ela, mencionadas anteriormente, provocou uma adaptação dos sistemas normativos contemporâneos, permitindo a expansão da representação processual coletiva e difusa.

Já a Terceira Onda, denominada de "Acesso à representação em juízo", visa a uma concepção mais ampla de acesso à Justiça, e um novo enfoque de acesso a ela. Esta Onda formou-se e ainda não se esgotou, buscando a superação do chamado "obstáculo processual". Nesta Onda, Mauro Cappelletti e Bryant Garth demonstram algo muito além do que foi tratado na primeira e segunda onda, trata-se de inovações, revelando-se importantíssimo trazer à baila a figura dos Juizados Especiais "criados não apenas para desafogar o Judiciário, mas também para abrir portas para o acesso à Justiça nos casos de menor complexidade" (1988, p. 15).

A criação de Juizados Especiais, na contramão do procedimento ritualizado e ordinário, visou a incluir casos frequentemente marginalizados, de lides advindas de pessoas sem condições de serem representadas por advogados particulares. Ademais, proporcionam um incremento de oralidade a um nicho calcado e desenvolvido na linguagem formal, escrita e com bordões distantes da grande sociedade. Eis o texto, quiçá garantia, trazida pelo artigo 98 da Constituição Federal de 1988:

A União, no Distrito Federal e nos Territórios, e os Estados criarão:

I - juizados especiais, providos por juízes togados, ou togados e leigos, competentes para conciliação, o julgamento e execução das causas cíveis de menor complexidade e infrações penais de menor potencial ofensivo, mediante os procedimentos oral e sumaríssimo, permitidos, nas hipóteses previstas em lei, a transação e o julgamento de recursos por turmas de juízes de primeiro grau (BRASIL, 1988, p. 127).

Em suma, a Terceira Onda busca ao movimento de acesso à Justiça novas alternativas para resolução de conflitos que não restritas ao ordenamento processual, normalmente causador de paixões e conflitos. Contempladas no plano do pluralismo jurídico, constata-se que algumas destas alternativas já estão sendo aceitas para dirimir litigiosidades, por exemplo, a mediação, a conciliação e a arbitragem, entre outras. Opera, assim, uma possível sinalização inicial de reformulações - ainda insubsistentes como se passará a ver - que podem indicar o início da ruptura com o paradigma individualista e formalista de processo civil.

Frisa-se, todavia, que não apenas a utilização de modos alternativos, mas também a reformulação do iter procedimental, também defendido pela Terceira Onda, será capaz de atrelar jurisdição à efetividade na tutela de direitos emergentes. É preciso retirar a processualística brasileira, conforme já explorado, do culto ao rito ordinário-plenário, o qual tradicionalmente afasta o juízo do caso concreto, fazendo com que sua percepção se dê "fase a fase" (ISAIA, 2010, p. 86), gradativa e, por consequência, sem uma compreensão conjunta com a aplicação do Direito. Nesse mesmo sentido, a respeito do assunto, leciona Jânia Maria Lopes Saldanha:

Admitindo-se que nenhum direito pode ser absolutizado, a situação pode ter outro enfoque ao se agregar à própria noção de cidadania um sentido substancial. No lugar dos pobres limites das relações obrigacionais, o que a Jurisdição tem recebido são demandas em que, na ordem do dia, estão reinvindicações ligadas aos direitos humanos de segunda e terceira geração, como moradia, saúde, educação, proteção ao meio ambiente, direitos das minorias e tantas outras categorias de direitos que impõem uma diversa perspectiva de proteção jurisdicional para serem atendidas com eficácia (2011, p. 204). 
Não seria de bom alvitre, portanto, deixar que um procedimento de contraditório prévio e cognição exauriente, calcado no ideário individualista, fosse o caminho de instalação de uma série inovadora de direitos sociais fundamentais, destinados à proteção do gênero humano, como o são o meio ambiente, a autodeterminação dos povos, o direito de comunicação e o direito derivado das relações de consumo. Preocupado com a efetivação dos direitos é a contribuição de Luiz Guilherme Marinoni:

Para tal análise é evidentemente necessário identificar o fundamento do procedimento diferenciado, ou meIhor, a necessidade de se restringir a alegação do réu para se permitir a tutela do direito. $O$ direito material que está sendo tutelado de forma diferenciada deve justificar a restrição da defesa. Essa restrição deve encontrar amparo na necessidade de tutela dos direitos e na Constituição Federal (2000, p. 445).

Desse modo, o que se pretende apontar aqui, salvo melhor juízo, é a necessidade de construção, via alteração legislativa, de espaços de sumarização processual, consistentes na abertura de um momento no iter procedimental, ainda na fase postulatória, em que, mediante exacerbação da oralidade, se possa garantir prerrogativas equânimes para autor e réu, com a necessária e imprescindível aproximação do intérprete/juiz às circunstâncias pulsantes do caso concreto. ${ }^{15}$ Trabalha-se aqui, com um contraditório concomitante e diferido, de maneira muito semelhante à justificação prévia, oriundas das Ações Possessórias de posse nova, ${ }^{16}$ ou à atual audiência de conciliação ou de mediação, prevista no atual Código de Processo vigente.

A título de exemplificação, Adalberto Hommerding, questiona: Como explicar ao cidadão, detentor de um direito, que este mesmo direito só poderá ser usufruído daqui a alguns anos, apesar de ter ficado demonstrado no processo que é ele quem tem razão? Ou, como explicar que a sentença, em que pese ter condenado seu adversário a lhe pagar, ainda não deu o direito que pretende, podendo, a mesma, ainda ser "embargada"? Ou pior, como explicar que, segundo o "entendimento majoritário" ou a "jurisprudência dominante", o seu recurso não será analisado por quem deveria ser? Ou, por fim, que o juiz adotou a "corrente forte" do Tribunal e desconsiderou a singularidade do seu caso? (ISAIA, 2010, p. 95-96).

Apenas a reformulação desta ordinariedade - procedimento plenário-cognitivo - vigente, acompanhada da reestrutura da própria concepção de processo, jurisdição e relação processual, é que podem acarretar a devida e esperada constitucionalização do Processo Civil brasileiro (MARINONI, 2000, p. 412). Tal assertiva se justifica na medida em que a jurisdição efetiva simboliza garantia de uma constituição pujante, a qual, por seu turno, representa uma democracia fortalecida. A ineficiência ou inefetividade da tutela jurisdicional provoca, ato contínuo, a própria descrença nos poderes do Estado e na própria disposição presente no ordenamento vigente, de modo a também acarretar reflexos na força da democracia.

Um Estado que resista em abandonar a ideologia liberal, contentando-se com uma prestação jurisdicional exclusivamente embasada no modelo processual inspirado no individualismo e no liberalismo que marcaram indelevelmente o século 19 , sem nenhum comprometimento com a garantia do acesso à Justiça, e que dependa de antiquadas e obsoletas estruturas institucionais, será impotente relativamente ao anseio do alcance da justiça social e jamais viabilizará a formação do verdadeiro Estado Democrático (CARNEIRO, 2000, p. 17-18). É necessário aproximar as partes da máquina estatal decisória e a real percepção do Direito alegado por aquelas.

Logo, o Direito Processual, como ciência atrelada à historicidade, permeável pelas contingências evolutivas próprias sociedade, como verdadeiro produto desta, há de estar em consonância com esta, pois de nada adianta a provisão formal de uma gama de direitos, inclusive estes alicerçados na base democrática do Estado, sem termos um Direito Processual Civil mergulhado do mesmo paradigma. Justamente, esta constitucionalização do referido ramo do Direito, seja mediante uma readequação legislativa ou propriamente judicial, perfaz-se o objetivo que se tentou demonstrar nas linhas antecedentes.

\footnotetext{
${ }_{15}$ Proposta parecida foi elaborada por Cristiano Becker Isaia, o qual teceu considerações sobre ser possível se pensar em novos loci processuais sumarizados, relacionados a um Judiciário difundido, que aprenda a reconhecer as diferenças por meio de um poder compartilhado por todos os sujeitos do processo, numa funcionalidade compatível às exigências constitucionais, tanto no que se refere a seu conteúdo substancial quanto o que toca ao respeito às garantias processuais constitucionais. In: ISAIA, Cristiano Becker. op. cit., 2010, p. 128.

${ }^{16}$ Terminologia dada às Ações Possessórias propostas há menos de um ano e dia da turbação ou do esbulho.
} 


\section{Direito自

\section{CONCLUSÃO}

A partir da elaboração do presente trabalho, constatou-se que existem, de fato, mazelas deixadas pelo sistema processual civil vigente, principalmente na tutela de direitos transindividuais, uma vez que sua jurisdição está imersa em um déficit de realidade, oriundo principalmente da supervalorização do processo de conhecimento e seu corolário rito ordinário (por natureza, plenário e declaratório). Tal procedimento, ideologicamente, vem mantendo o processo no interior da tradição liberal preconizada no século 17 e exaltando, sem dúvida, a obsessão pelo encontro de certezas e verdades eternas no trato de direitos subjetivos individuais.

Considerando a contemporaneidade vivida pela sociedade atual, verificou-se a necessidade de readequação da jurisdição processual civil a esse novo paradigma de modernidade, no qual a solidariedade, a coletividade e a transindividualidade ganham proeminência. No ponto, mediante a influência das Ondas Renovatórias de acesso à Justiça elaboradas por Mauro Cappelletti, foi possível perceber a existência de potenciais caminhos a fim de promover a aproximação do processo e, logicamente, da própria jurisdição civil, aos valores trazidos pela Carta Política.

O acesso à Justiça, tanto sob a modificação do rito quanto ao emprego de técnicas processuais diferenciadas, com efeito, proporcionam um ganho de efetividade ao processo civil vigente, de modo a fortalecer, indiretamente, o próprio regime democrático, pois a judicialização exponencial advinda do século 20 , com sua consequente tutela efetiva, fortalece o atendimento dos anseios representados pelas minorias. Dito isso, essa efetivação jurisdicional faz emergir a função contramajoritária do Direito Processual Civil, fazendo com que o referido ramo formal do Direito esteja, ideologicamente, contribuindo para a manutenção do tão sonhado Estado Democrático de Direito.

Por meio de uma reformulação procedimental, com a abertura de espaços sumarizados, nos quais haja a supervalorização da oralidade e a participação democrática dos envolvidos, é que se pode aproximar o Direito Processual Civil dos parâmetros constitucionais vigentes. Ademais, na senda de revitalização da jurisdição e do processo civil, diante dos direitos emergentes no século 20 , fica evidenciado que as ciências derivadas da compreensão não podem nem devem ficar atreladas a juízos cartesianos que desejam torná-las demonstrativas e exatas, como antigamente se quis. A ciência do Direito há de estar atrelada ao tempo.

\section{REFERÊNCIAS}

BONAVIDES, Paulo. Curso de Direito Constitucional. 24. ed. São Paulo: Malheiros, 2009.

BRASIL. Constituição da República Federativa do Brasil. Brasília, DF: Senado Federal: Centro Gráfico, 1988.

BRASIL. Lei no 5.869, de 11 de janeiro de 1973. Institui o Código de Processo Civil. Disponível em: http://www.planalto.gov.br/ ccivil_03/leis/15869.htm. Acesso em: 18 dez. 2014.

BRASIL. Lei n. 13.105, de 16 de março de 2015. Código de Processo Civil. Disponível em: http://www.planalto.gov.br/ccivil_03/_ ato2015-2018/2015/lei/l13105.htm. . Acesso em: 24 mar. 2015.

CANOTILHO, Joaquim José Gomes. Direito Constitucional e teoria da constituição. 2. ed. Coimbra: Livraria Almedina, 1998.

CAPELLARI, Eduardo. A crise da modernidade e a constituição: elementos para a compreensão do constitucionalismo contemporâneo. Rio de Janeiro: América Jurídica, 2004.

CAPPELLETTI, Mauro; GARTH, Bryant. Acesso à justiça. Tradução Ellen Gracie Northfleet. Porto Alegre: Sérgio Antônio Fabris, 1988.

CARNEIRO, Paulo Cézar Pinheiro. Acesso à justiça - juizados especiais cíveis e ação civil pública: uma nova sistematização da Teoria Geral do Processo. 2. ed. Rio de Janeiro: Forense universitária, 2000.

FERREIRA FILHO, Manoel Gonçalves. Aspectos do direito constitucional contemporâneo. 2. ed. São Paulo: Saraiva, 2009.

HOMMERDING, Adalberto N. Fundamentos para uma compreensão hermenêutica do processo civil. Porto Alegre: Livraria do Advogado, 2007.

ISAIA, Cristiano Becker. Processo civil, atuação judicial e hermenêutica filosófica: a metáfora do juiz-instrutor e a busca por respostas corretas em direito: facticidade e oralidade. Curitiba: Juruá, 2010.

MARINONI, Luiz Guilherme. Novas linhas do processo civil. 4. ed. São Paulo: Malheiros, 2000.

MELLO, Michele Damasceno Marques. 2010. Considerações sobre a influência das ondas renovatórias de Mauro Cappeletti no ordenamento jurídico brasileiro. Disponível em: https://www.avm.edu.br/docpdf/monografias_publicadas/k212492.pdf. Acesso em: 29 out. 2019. 
NUNES, Dierle. Curso de Direito Processual Civil: fundamentação e aplicação. Belo Horizonte: Fórum, 2011.

OEA. Organização dos Estados Americanos. Convenção Americana de Direitos Humanos". 1969. Disponível em: http://www. oas.org/es/council/AG/regular/46RGA/documents.asp. Acesso em: 22 jan. 2019.

PÉREZ LUÑO, Antonio Enrique. Los derechos humanos en la sociedad tecnológica. Madrid: Editorial Universitas, 2006.

SALDANHA, Jânia Maria Lopes. Substancialização e efetividade do direito processual civil - a sumariedade material da jurisdição: proposta de estabilização da tutela antecipada em relação ao projeto de novo CPC. Curitiba: Juruá, 2011.

SARLET, Ingo Wolfgang. A eficácia dos direitos fundamentais: uma teoria geral dos direitos fundamentais na perspectiva constitucional. 10. ed. Porto Alegre: Livraria do Advogado Editora, 2010.

SILVA, Ovídio A. Baptista da. Curso de processo civil: processo de conhecimento. 5. ed. São Paulo: Editora Revista dos Tribunais, 2000. Vol. 1.

SILVA, Ovídio A. Baptista da. Jurisdição e execução na tradição romano-canônica. 3. ed. Rio de Janeiro: Forense, 2007.

SILVA, Ovídio A. Baptista da. Processo e ideologia: o paradigma racionalista. Rio de Janeiro: Forense, 2006.

STRECK, Lenio Luiz. Jurisdição constitucional e hermenêutica: uma nova crítica do direito. Porto Alegre: Livraria do Advogado, 2002.

THEODORO JÚNIOR, Humberto. Curso de Direito Processual Civil: teoria geral do direito processual civil e processo de conhecimento. Rio de Janeiro: Forense, 2010.

THEODORO JÚNIOR, Humberto. O Processo Civil brasileiro: no limiar do novo século. Rio de Janeiro: Forense, 2002. 